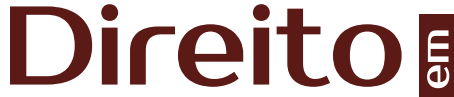 \\ Debate
}

Revista do Departamento de Ciências Jurídicas e Sociais da Unijuí Editora Unijuí - Ano XXX - n. 56 - jul./dez. 2021 - ISSN 2176-6622

\section{FRONTEIRA: Trânsitos, Sensos e Dissensos Compartilhados}

http://dx.doi.org/10.21527/2176-6622.2021.56.10823

Recebido em: 25/5/2020

Aceito em: 18/11/2020

José Antônio Peres Gediel Universidade Federal do Paraná - Setor de Ciências Jurídicas. Curitiba/PR, Brasil.

Autor correspondente. Universidade Federal da Integração Latino-Americana - Corregedoria Seccional da Unila. Av. Sílvio Américo Sasdelli, 1842 - Vila Residencial A. Foz do Iguaçu/PR, Brasil. CEP 85866-000. http://lattes.cnpq.br/8126918920140047. https://orcid.org/0000-0002-3942-042X. fernandocesarmb@gmail.com

\section{RESUMO}

O objetivo deste artigo é analisar o modo como as fronteiras são conceituadas pelas diversas áreas do conhecimento e pelo Direito estatal. A pesquisa bibliográfica exploratória permite aproximar abordagens que concebem a fronteira não apenas como uma questão teórica ou metodológica, mas como uma realidade construída historicamente e socialmente significada e ressignificada por seus habitantes. Discute os efeitos que as ações do Estado causam sobre a compreensão dos habitantes a respeito da sua própria região e atividades. Examina as singularidades dos trânsitos fronteiriços que ocorrem na região da fronteira trinacional, formada pelo Brasil, pela Argentina e pelo Paraguai. Conclui, apontando para a necessidade de a fronteira ser tomada como território fronteiriço com dinâmicas sociais específicas e ações estatais que a reconheçam na sua especificidade e complexidade.

Palavras-chave: Fronteira; mobilidade humana; pluralidades conceituais; controle estatal.

\section{BORDERS: SHARED TRANSITS, SENSES AND DISSENTS}

\section{ABSTRACT}

The objective of this article is to analyze how borders are conceptualized by different areas of knowledge and in the Brazilian Federal law. Exploratory bibliographical research allows to approximate perspectives that conceive borders not only as a theoretical or methodological question, but as a reality that has been historically constructed and socially signified and resignified by its inhabitants. This article discusses the effects of State actions on the inhabitants' understanding of their region and activities. It examines the peculiarities of border transits in the tri-national border region formed by Brazil, Argentina, and Paraguay. It concludes by emphasizing the need for this border to be treated as a border territory that has specific social dynamics and that requires State actions to recognize its specificity and complexity.

Keywords: Borders; human mobility; conceptual pluralities; state control. 


\section{INTRODUÇÃO}

A palavra fronteira, embora polissêmica, tem no cerne de seus sentidos a noção de limites. Esses limites, no caso de Estados-Nação, foram definidos na modernidade por uma perspectiva de território, governo ou jurisdição, e não necessariamente de povos, culturas e línguas. Essa perspectiva vem sendo orientada por ideologias nacionalistas em torno de comunidades imaginadas (ANDERSON, 2008).

Conceber a fronteira como limite significou e significa, por um lado, tensões e conflitos, porque culturas e línguas poucas vezes se identificam como uma comunidade em termos de Estado-Nação, uma vez que são agrupadas, juridicamente, em conformidade com um território nacional, sob um determinado domínio político. Por outro lado, é também o lugar que coloca a noção de Estado-Nação em discussão, pois o Estado marca sua força e seu poder por meio de leis e práticas que, omissivas ou comissivas, nem sempre encontram ressonâncias nas dinâmicas sociais e culturais da fronteira.

Para dar conta da complexidade que permeia esses conceitos e situações, o artigo procura descrever, inicialmente, o modo pelo qual as fronteiras são percebidas por vários ramos da Ciência, para, em seguida, destacar que a noção de fronteira não constitui apenas uma questão teórica ou metodológica, mas também política. Cada uma das formas de análise ou investigação da fronteira guarda em si formas distintas de apreender e compreender o espaço e a própria realidade fronteiriça.

Nessa mesma direção, o tema escolhido também visa a demonstrar como a forma de compreender a fronteira aponta para a centralidade de ações estatais que incidem nessas regiões, por meio de políticas coordenadas ou ações isoladas que pretendem, em alguma medida, definir, consolidar, alterar ou controlar a fronteira. O problema que se coloca ao se examinar a ação do Estado nessa região é a incidência de ações que operam com registros de controle diferenciados para as atividades comerciais e para o trânsito de pessoas, aspectos que estão imbricados na mobilidade humana.

Esses aspectos indicam a necessidade de intensificação de diálogo entre Estados, que apontem para a construção de políticas públicas que levem em consideração as especificidades da região e as atividades desenvolvidas por seus habitantes (MOURA; CARDOSO, 2014). A variabilidade nos modos de agir do Estado em relação a cada área de fronteira revela a existência de paradoxos na ação estatal e cria tensões implicadas diretamente na vida de diferentes grupos sociais que se movem constantemente pela (e na) fronteira.

Por tais razões, constitui a opção metodológica deste estudo abordar as compreensões sobre a fronteira, a partir da ótica do Estado-Nação, e a partir da ótica da própria fronteira, levando em consideração o trânsito de residentes fronteiriços que, diariamente, se movimentam nessa região e que se opõem, em sua ação cotidiana, à delimitação da fronteira legalmente demarcada e controlada. Nesse cercamento territorial estatal, diante da movimentação transfronteiriça de populações, esboçam-se, de maneira fluída e por vezes imperceptível, "espaços vazios" (ALBUQUERQUE, 2009) de poder estatal.

Toma-se como base argumentativa e interpretativa os espaços vazios entre a particularidade da região de fronteira trinacional, Brasil, Argentina e Paraguai, dada a excepcionalidade das suas condições históricas, sociais, culturais, simbólicas e políticas, que desafiam os institutos jurídico-normativos e as políticas pensadas para a fronteira com a finalidade de regulamentar e controlar a atividade das populações e o trânsito de mercadorias e serviços.

Para o desenvolvimento da análise proposta, o artigo está organizado em três seções: na primeira são estudadas as formas de compreender a fronteira e possíveis implicações dessas compreensões; na segunda seção apresenta-se uma descrição de ações do Estado e sua relação com as dinâmicas sociais da fronteira; na terceira são apresentadas singularidades dos trânsitos fronteiriços que têm lugar na região de fronteira trinacional, formada pelo Brasil, pela Argentina e pelo Paraguai, no encontro das cidades de Foz do Iguaçu, Puerto Iguazú e Ciudad Del Este, respectivamente.

\section{A FRONTEIRA COMO QUESTÃO TEÓRICA}

Tomar a fronteira como objeto de pesquisa significa debruçar-se sobre um tema que constantemente e mais recentemente - tem despertado a atenção de pesquisadores das mais variadas áreas do conhecimento. Em que pese o fato de a fronteira, como objeto de pesquisa, não ser necessariamente um tema contem- 
porâneo ou novo, trata-se de um tema que se atualiza, na mesma medida em que as dinâmicas sociais que constituem esse território se atualizam.

É nesse sentido que são desenvolvidas pesquisas em diversas áreas da Ciência na fronteira e sobre a fronteira, como Albuquerque $(2009,2010)$, Cardin (2011, 2015), Cardin e Albuquerque (2018), Catta (2002, 2009, 2011) nas Ciências Sociais; Carneiro (2017), Farina (2015), Slomp (2014), Barbosa (2016, 2018) no Direito; Lima (2011), Nascimento (2010) na Geografia; Da Silva; Pires-Santos; Jung (2016) na Linguística; Rabossi (2011, 2019), Silva $(2011,2012)$ na Antropologia, entre outras que, em comum, investigam os diversos elementos que constituem as regiões fronteiriças.

Metodologicamente, neste artigo lança-se mão de pesquisa exploratória de trabalhos e investigações sobre (e em) fronteiras que o cientista social Eric Gustavo Cardin $(2011,2015)$ têm desenvolvido na região da fronteira trinacional. Outros autores de diversas áreas são revisitados para ampliar o debate, no que se refere a questões comuns ao tratamento que o Estado dispensa a áreas fronteiriças.

Albuquerque e Cardin (2018) destacam que, até o início do século 20 as pesquisas realizadas na Sociologia compreendiam a fronteira como um objeto circunstancial ou secundário, ou seja, a fronteira não era tomada como um objeto teórico. Nesse sentido, outros autores consideram que a região de fronteira ocupava lugar nas pesquisas das Ciências Sociais para pensar as relações entre uma região e "frentes de expansão/colonização, zonas de contato/conflito, relações entre identidade e diferença" (p. 117).

Embora as pesquisas relacionadas à fronteira tenham apresentado essa característica mais delimitadora ou limitadora, o fato é que mais recentemente se reconhece que a fronteira tem se transformado em um grande espaço de articulação e de diálogo entre grandes temas de pesquisa (CARDIN; ALBUQUERQUE, 2018). Para além disso, o que se propõe é “[...] questionar permanentemente as perspectivas de 'redução' da fronteira a limites políticos-jurídicos, a controles migratórios ou a um problema de segurança nacional ou regional associado ao tráfico ou/e ao terrorismo" (CARDIN; ALBUQUERQUE, 2018, p. 119).

Essa discussão procura, por um lado, compreender as diversas possibilidades de temas de pesquisa que emergem em uma região de fronteira - o que, por si só, revela as diversidades presentes nas singularidades dessa região. Por outro, identifica a necessidade de deslocar formas de compreensão da fronteira que a reduzem a temas ou problemas limitadores de sua potencialidade e de suas características mais essenciais, por exemplo, um espaço de diversidades culturais, étnicas, linguísticas e legais, uma vez que se trata de uma região em que há constante diálogo entre os Estados e seu conjunto jurídico-normativo.

Correndo o risco de relativizar a concepção de fronteira subjacente a essa ideia, equivaleria dizer que se trata, na verdade, de contrapor, mas não opor, a compreensão dessa região a partir de seus problemas à noção de um espaço como território fronteiriço, historicamente construído e socialmente significado pelas pessoas que nele habitam, constituindo, na verdade, "uma linha material ou imaginária, historicamente institucionalizada, que se esmaece diante da interação na produção/construção real do espaço" (MOURA; CARDOSO, 2014, p. 265).

Exemplificativamente, quando considerada a fronteira trinacional em análise, o que se tem verificado é que muitos saberes e práticas que são atribuídos a essa região relacionam-se a uma construção que é pretérita, ou seja, há muito tempo argentinos, paraguaios e brasileiros atribuem significados e constroem esse território, criado anteriormente à delimitação oficial dos três Estados. Por exemplo, nas relações de trabalho de argentinos, brasileiros e paraguaios, no sistema de produção conhecido como obrages ${ }^{1}$ (WACHOWICZ, 1987), atribuem um significado especial a essas atividades compartilhadas nos três países.

A história e a localização geográfica das cidades de Foz do Iguaçu, de Ciudad Del Este e de Puerto Iguazú sinalizam para a necessidade de essa região de fronteira ser pensada coletivamente, pelas cidades que a compõem, a partir das relações e das dinâmicas sociais que se estabelecem nesse espaço, por meio dos cidadãos que nela residem e lhe atribuem significados, de maneira que "as fronteiras e os limites refletem e propiciam

\footnotetext{
Constituía-se em um sistema no qual fazendas recrutavam empregados para trabalharem em campos de extração de erva-mate e madeira. A posse da maior parte dessas fazendas estava concentrada nas mãos de proprietários argentinos, segundo Wachowicz (1987, p. 47-48).
} 
interdependências e dinâmicas inter-relacionais que extrapolam a formalidade, em ações capazes de suplantar - de forma legal ou não - as barreiras de sua existência" (CARDOSO; MOURA, 2012, p. 206).

Esses cidadãos são de várias nacionalidades e, ainda que a maioria seja da Argentina, do Brasil e do Paraguai, tanto no passado quanto no presente, outras nacionalidades somam-se a essas e contribuem para configurar essa região, como é o caso de cidadãos de origem asiática e de diversos grupos árabes, presentes na região (SILVA, 2011).

Compreender, hoje, a fronteira real, formada por esses três países que guardam entre suas histórias fatos comuns às suas origens, à sua formação e à sua constituição, implica, necessariamente, considerar a relevância dos fatos ocorridos nesse espaço geográfico construído historicamente. Afinal, remetemo-nos a uma região cuja titularidade dos Estados-Nação pertence ao povo argentino, ao povo paraguaio e ao povo brasileiro. Nesse sentido, Farina destaca a região como um espaço de construção de uma identidade própria que decorre "das relações que se estabelecem ao longo do tempo, historicamente construídas pelos sujeitos que compartilham a vida em sociedade na fronteira" (2015, p. 24).

Essa identidade própria da fronteira trinacional, para Luiz Eduardo Pena Catta (2011), deve-se, substancialmente, ao fato de ser resultado de um processo mais demorado de ocupação e de desenvolvimento, diferenciando-a de outras regiões do país, sobretudo porque inicialmente não contou com o investimento de recursos ou com interesses governamentais.

Além disso, para esse autor, um processo de ocupação mais efetiva teve início no ano de 1965, com a conclusão da Ponte Internacional da Amizade, no Rio Paraná, aproximando o Brasil e o Paraguai, e com a inauguração da BR-277, em 1970, facilitando o tráfego entre Foz do Iguaçu e Curitiba. É a partir desses marcos que Foz do Iguaçu tem seu desenvolvimento acelerado e seu comércio intensificado, principalmente com Ciudad del Este, no Paraguai.

Nessa perspectiva, inevitavelmente, destacam-se, também, as alterações socioeconômicas em virtude da construção da Hidrelétrica de Itaipu, responsável pela reconfiguração da região, antes, durante e depois da conclusão das obras. Se a construção da hidrelétrica significou um grande aumento populacional e uma reconfiguração do cenário socioeconômico à época, seu término também deixou marcas profundas na definição de elementos importantes para a redefinição da cidade e de toda a região, especialmente nas relações de trabaIho e nos processos de segregação" do espaço urbano, decorrente das "Vilas de Itaipu".

Em que pesem as influências do processo de formação da cidade de Foz do Iguaçu estarem diretamente relacionadas aos investimentos brasileiros em áreas de infraestrutura, as narrativas a respeito da formação e da consolidação dessa região de fronteira mostram como a cidade de Foz do Iguaçu também teve sua configuração alterada em razão de mecanismos políticos e de alterações econômicas, como a passagem do sistema de obrages para as madeireiras e empresas de erva-mate nacionais, para a atividade de comércio internacional, que persiste até os dias de hoje.

Para além disso, é necessário reconhecer que essa fronteira possui particularidades que correspondem não apenas ao seu processo de construção, impulsionado pelo poder público e pelos interesses que moviam atividades econômicas mais relevantes. Ela se constitui, sobremaneira, pelo trânsito das pessoas que vivem em um e em outro lado dos limites oficiais e é esse trânsito diário que permite pensar na existência de um espaço que não é necessariamente brasileiro, argentino ou paraguaio, mas um espaço fronteiriço trinacional. Nesse sentido, "essa incessante mobilidade torna a faixa de fronteira um espaço contínuo, produzido pelas estratégias de sobrevivência e interação cotidianas de seus povos, fragmentado e carente quanto a políticas e práticas de integração" (CARDOSO; MOURA, 2012, p. 218).

\footnotetext{
Para maiores informações a respeito da segregação socioeconômica e espacial causadas pela construção da Hidrelétrica de Itaipu, remetemos à leitura do trabalho de: SOTUYOU, Patrícia Claudia Godoy. Segregação urbana: estudo de caso das vilas de Itaipu. Florianópolis, 1998; $150 \mathrm{p}$.

3 As Vilas de Itaipu foram conjuntos habitacionais construídos para abrigar os funcionários que trabalhavam na construção da Usina Hidrelétrica de Itaipu e aqueles que também seriam responsáveis pelo seu funcionamento. Foram construídas três vilas: A, B e C, destinadas aos barrageiros (responsáveis pela construção da barragem), aos funcionários de nível médio e técnico e aos funcionários de funções mais elevadas dentro da Usina, respectivamente. Inicialmente, todas as Vilas de Itaipu - embora estivessem localizadas no município de Foz do Iguaçu - eram totalmente independentes da administração municipal (Aranha, 2013).
} 
A centralidade da importância dessa discussão inicial sobre fronteira trinacional, e seus processos de constituição e construção, contrapõe-se à concepção da fronteira somente como uma faixa ou como limite definidor de um território. Para isso é necessário pressupor que os elementos caracterizadores desse espaço são as tensões desiguais entre as forças, que também podem ser os Estados, e toda a sorte de controle político, econômico e jurídico, que tentam permear e orientar as relações que ali são estabelecidas.

Compreender a fronteira como uma faixa ou como limite definidor de um território significa examiná-la a partir da adoção ou do estabelecimento de elementos externos, sem considerar suas especificidades sociais, econômicas e, sobretudo, históricas. Tal redução de sentidos tampouco permitiria uma aproximação desse espaço com elementos que revelam sua identidade e as redes de sociabilidade que têm sido construídas ao longo dos séculos. É por isso que se torna fundamental compreender a fronteira como "territórios de oportunidades, de trânsitos, de intercâmbio cultural e de expressões identitárias" (CARDIN; ALBUQUERQUE, 2018, p. 119) e não apenas como limites geopolíticos que separam um lado do outro da fronteira.

\section{AÇÕES DE ESTADO E MOBILIDADE FRONTEIRIÇA: DISSENSOS E AMBIVALÊNCIAS}

O risco de abordagens reducionistas sobre as fronteiras pode resultar em uma visão unilateral de um mesmo objeto, desconsiderando todas as "potencialidades" (CARDIN; ALBUQUERQUE, 2018, p. 119). A adoção de perspectiva teórica distinta permite valorizar o que acontece no intervalo entre a forma como a atuação estatal concebe a fronteira e os significados que a ela são diariamente atribuídos, seja por aqueles que todos os dias por ela transitam para trabalhar, ou para ter acesso a direitos sociais como saúde e educação, seja por aqueles que se deslocam para atividades de comércio. São trânsitos que apontam para "a busca pela realização de direitos que se confundem entre os lados da fronteira, muitas vezes dificultados pelos obstáculos de políticas de controle inadequadas" (CARDOSO; MOURA, 2012, p. 218).

O trânsito transfronteiriço escapa do controle absoluto dos poderes estatais dos países e instaura um vazio de poder que leva os Estados a considerarem a fronteira como um território que precisa, necessariamente, ser controlado, permitindo que se justifique esse controle por questões estratégicas de defesa nacional e pela necessidade de prevenção ou diminuição da violência.

As atividades relacionadas ao controle das regiões de fronteira têm sido utilizadas com finalidades específicas por serem consideradas áreas em que há grande incidência de criminalidade. A cooperação internacional que não ocorre em relação à melhoria das condições de vida das populações fronteiriças verifica-se de maneira efetiva na questão de ações de controle migratório e de trânsitos fronteiriços.

Com essa finalidade, o Decreto no 7.496, de 8 de junho de 2011 - instituiu o Plano Estratégico de Fronteiras, revogado pelo Decreto 8.903, de 16 de novembro de 2016, que institui o Programa de Proteção Integrada de Fronteiras e organiza a atuação de unidades da administração pública federal para sua execução. Ambos os institutos preveem como finalidade "o fortalecimento da prevenção, do controle, da fiscalização e da repressão aos delitos transfronteiriços" (BRASIL, 2011).

É a partir do Plano Estratégico de Fronteiras que o Ministério da Justiça instituiu a Estratégia Nacional de Fronteiras - Enafron ${ }^{4}$ - que se pôs em execução um conjunto de ações do governo federal - em cooperação com outras esferas de governo - para tornar as forças policiais presentes nas regiões de fronteira e, com isso, atuar na repressão a crimes que supostamente acontecem nesse espaço fronteiriço, notadamente crimes relacionados ao tráfico de drogas, de armas de fogo, contrabando e descaminho e crimes ambientais.

Nesse mesmo sentido, o artigo 2o do Programa de Proteção Integrada de Fronteiras estabelece como uma de suas diretrizes: "a atuação integrada e coordenada dos órgãos de segurança pública, dos órgãos de inteligência, da Secretaria da Receita Federal do Brasil do Ministério da Fazenda e do Estado-Maior Conjunto das Forças Armadas, nos termos da legislação vigente", ao passo que o artigo 3 o do mesmo Programa apresenta como objetivo: "integrar e articular ações de segurança pública da União, de inteligência, de controle aduanei-

\footnotetext{
NEVES, Alex Jorge et al. (Orgs.) Segurança pública nas fronteiras, diagnóstico socioeconômico e demográfico: estratégia nacional de segurança pública nas fronteiras (Enafron). Brasília: Ministério da Justiça e Cidadania, Secretaria Nacional de Segurança Pública, 2016.
} 
ro e das Forças Armadas com as ações dos Estados e Municípios situados na faixa de fronteira, incluídas suas águas interiores, e na costa marítima" (BRASIL, 2016b).

A própria ideia de criminalidade ou de repreensão à atividade delitiva na fronteira, no entanto, adquire contornos bastante diferentes se comparada com a prática de crimes análogos em outras regiões do país. A atividade criminal e, em certa medida, a própria "atividade estatal" tentando "controlar" essas práticas, seja por meio da prevenção quanto por meio da repreensão, assume contornos diferentes nessa região, fazendo com que conceitos como lícito e ilícito, legal e ilegal, contrabando e descaminho, assumam linhas tênues e ambíguas entre si (CARDIN, 2015; SILVA, 2011, 2012).

Essa ambiguidade das ações de controle do Estado em relação às atividades e dinâmicas sociais na fronteira trinacional também foi investigada por meio da análise das relações de trabalho, que se verificam no "circuito sacoleiro," no âmbito do qual "o bem e o mal, o ético e o antiético, o moral e o imoral, o legal e o ilegal parecem não mais reconhecerem suas definições e suas possibilidades. Os limites que separam essas diferentes definições tornam-se fluidos" (CARDIN, 2015, p. 67-68).

Essas relações antagônicas são analisadas a partir da própria estrutura interna do circuito sacoleiro, no qual há funções e papéis muito bem definidos, pois cada integrante sabe exatamente quais são suas atribuições, suas prerrogativas e os limites de cada uma dessas funções. ${ }^{6}$ Assim, aponta-se para a possibilidade de duas análises: uma especificamente relacionada aos trabalhadores integrantes do circuito, responsáveis pelo transporte de mercadorias, que retiram dessa atividade, de natureza laboral, sua subsistência, e a outra relacionada àquelas atividades de transporte de mercadorias que não se constituem tão somente em meios de sobrevivência, mas em atividades de oportunistas e criminosos.

Essas atividades também permitem identificar o tratamento dúbio que lhes é conferido pelo Estado, ao definir ou distinguir o lícito do ilícito, o legal do ilegal, e ao embaralhar tipos penais menos graves com os de maior gravidade, desconsiderando que as práticas sociais realizadas pelos integrantes do circuito sacoleiro são atividades laborais, que se relacionam diretamente a meios de subsistência que, inclusive, em muitos casos, são a única opção para alguns dos trabalhadores.

Tal situação divergiria bastante daquelas percebidas pelas atividades de contrabando de expressivas quantidades de mercadorias, nas quais estaria presente um interesse maior: a expansão do capital, razão pela qual essas forças denominadas legal e ilegal estão em permanente conflito e são constantemente ressignificadas nessa região de fronteira (CARDIN, 2015).

Essas dinâmicas estabelecidas nas áreas adjacentes da Ponte da Amizade, e mais especificamente nas margens do Rio Paraná, deixam claras as proximidades e os conflitos que historicamente têm ocorrido nesse espaço. As relações socioeconômicas da região são construídas a partir do próprio espaço físico da fronteira, como um dos elementos que favorece o livre trânsito de pessoas, sobretudo o de brasileiros para e no Paraguai, e o de paraguaios para e no Brasil. Depreende-se daí que as dinâmicas desse espaço são alteradas, seja por atuação do Estado ou por alterações no interior dos sistemas ou circuitos nela estabelecidos, nos quais as dinâmicas sociais e econômicas também são reconfiguradas.

Destaca-se que, quase sempre, essas relações desenvolvidas na região de fronteira são compreendidas - se é que chegam a ser - com uma certa ressalva quanto à sua legalidade, ou melhor, ilegalidade, dentro dos modelos fiscal e jurídico vigentes (CARDIN, 2015, p. 107). Assim, as atividades laborais estabelecidas nessa região constituem trabalho não pelo estabelecimento de vínculos formais de emprego, mas como resultado de transformações políticas, econômicas e migratórias. Essas atividades "movem-se ao (di) sabor de quem transita, sob uma dialética de ambiguidades - de fim e de início, de legal e de ilegal - que se manifesta em um mesmo espaço transitório, em que existe e inexiste o pertencimento". (CARDOSO; MOURA, 2012, p. 219).

Eric Gustavo Cardin define "o circuito sacoleiro como as relações entre os diferentes sujeitos sociais responsáveis pelo percurso trilhado pelas mercadorias disponibilizadas no mercado paraguaio e que entram no Brasil de forma ilegal" (2015, p. 223).

6 Cardin (2015, p. 72) apresenta algumas das funções que constituem o circuito sacoleiro: vendedores ambulantes no Brasil; vendedores fixos em lojas no Paraguai; laranjas; sacoleiros; cigarreiros; agenciador; freteiro; barqueiro; carregador; batedor; proprietário de porto. 
As alterações econômicas e políticas na região têm sua base de sustentação nas ações desenvolvidas pelo governo brasileiro para conter o transporte de mercadorias e no aumento "do número de trabalhadores que necessitam desenvolver atividades subterrâneas para sobreviver" (CARDIN, 2015, p. 125), mas se aproveitam, sobretudo, das grandes diferenças tributárias, políticas e econômicas praticadas pelo Brasil e pelo Paraguai. As grandes desigualdades entre os dois Estados agem como sustentáculos para relações de trabalho consideradas ilegais.

Há uma lógica que, muitas vezes, é invertida, quando se constata que todos esses obstáculos, ou que todo esse conjunto de esforços para dificultar a prática das atividades desses trabalhadores nessa região opõe-se à flexibilização ou à ausência de fronteiras fiscais para a instalação de parques industriais. Nessa direção, destaca-se que para a expansão do capital ou para o incentivo a práticas comerciais consideradas oficiais, a fronteira torna-se mais flexível do que para as relações de trabalho que têm lugar no interior do circuito sacoleiro (CARDIN, 2015, p. 207-208).

Além disso, observa-se, de outra maneira, a demarcação das relações de ambivalência estabelecidas nessa região. Em entrevista realizada por Eric Gustavo Cardin (2015) com Sandra, uma ex-integrante do circuito sacoleiro, que comenta as atividades desempenhadas durante três anos, no transporte de mercadorias de Ciudad Del Este para Foz do Iguaçu e relata que "[...] tinha um federal que mandava carta para falar quando eu deveria passar. Então ele olhava minha bagagem e não tomava nada, assim eu ganhava meu dinheirinho" (p. 96).

Não se trata aqui de detalhar em minúcias as práticas de trabalho dos agentes públicos, no caso exemplificado anteriormente, da Polícia Federal, que trabalham na região de fronteira. Tampouco cabe analisar sua legalidade ou existência atual dessas práticas, pois este não é o objetivo deste trabalho. $O$ que se objetiva com a transcrição do depoimento de Sandra é mostrar que também na fronteira trinacional há sistemas que funcionam e se fortalecem por meio do silêncio e da cumplicidade (CARDIN, 2015). Silêncio e cumplicidade colaboram diretamente para a construção e para o fortalecimento de invisibilidades na fronteira trinacional e agem na manutenção de desigualdades e da exclusão social dessa categoria de trabalhadores, são "diferenças sociais tornadas naturais e legítimas, sob o véu mascarador da pretensa igualdade e universalidade que habita a noção de dignidade" (SOUZA, 2003, p. 66).

Nesse sentido, materializa-se verdadeira dissonância entre as práticas de controle na região de fronteira e o que de fato mostram as dinâmicas das relações sociais que têm sido construídas social e historicamente, de forma que "a linha delimitadora dos Estados não interrompe as práticas do local" (KLEINSCHMITT, 2016, p. 47). A esse respeito, outras práticas de controle têm ganhado espaço na fronteira trinacional, por meios pelos quais esse hiato entre o que propõem as ações de controle e o que de fato mostra a realidade da fronteira permanece e se intensifica.

Especificamente em relação à cidade de Foz do Iguaçu, algumas ações levadas a cabo nas últimas décadas, a partir de 1990, alteraram significativamente o espaço urbano, e podem inclusive ter promovido alterações nos índices criminalidade e letalidade registrados na cidade. Assim,

a primeira política foi o projeto "Beira Rio", que promoveu a remoção das favelas que estavam nas barrancas do Rio Paraná [...]. A segunda política adotada no lado brasileiro foi a intensificação das forças de segurança para coibir o "circuito sacoleiro". A terceira política de controle está em desenvolvimento e diz respeito ao projeto "Beira Foz", que ganhou apoio da Itaipu Binacional e dos governos estadual e federal (KLEINSCHMITT, 2016, p. 40).

Em síntese, a análise ${ }^{7}$ dessas políticas revela que à medida que a primeira ação de controle foi adotada, ou seja, houve a revitalização da avenida Beira Rio, com a remoção de todas as famílias que moravam nas favelas da região, também houve aumento no número de mortes na cidade de Foz do Iguaçu, entre os anos de 1998 e 2006.

Os dados e informações referentes à relação entre violência, letalidade e criminalidade na fronteira trinacional, utilizados neste trabalho têm como fonte de informação a pesquisa realizada por Sandra Cristina Kleinschmitt. Para acesso a mais informações sobre sua pesquisa, remetemos à leitura de seu trabalho: KLEINSCHMITT, Sandra Cristina. As mortes violentas e as políticas de controle na Tríplice Fronteira. Tempo da Ciência. Toledo, v. 23. n. 46, 2016. p. 40-59. 
A segunda ação de controle instaurada na cidade, que primava pelo aumento da força policial na região para coibir ou diminuir as atividades realizadas no âmbito do circuito sacoleiro, alterou muitas das atividades consideradas ilícitas na cidade e diminuiu as taxas de letalidade em Foz do Iguaçu. As atividades ilícitas, no entanto, migraram e aumentaram em outras cidades da região.

Por fim, a terceira política de controle, que ainda está em andamento, é o Projeto Beira Foz, uma iniciativa pública e privada que pretende, por meio de projetos nas áreas econômica, ambiental, social, infraestrutura, entre outras, alterar o espaço urbano junto as margens dos Rios Paraná e Iguaçu.

Os dados revelam ainda que, por um lado, as ações de controle efetivadas pelo Estado não atingem os resultados esperados. Contrariamente, o que se depreende é que essas ações são instituídas em total desconsideração com aspectos importantes da fronteira trinacional, por exemplo, a constituição e a vida de famílias inteiras que residem na região e dependem, em muitos casos, exclusivamente, de atividades de comércio, muitas vezes criminalizadas, sem que se apresentem outras alternativas para essas pessoas. Essa situação também se verifica no caso de remoção das favelas para reconfiguração do espaço urbano, resultando em um aumento na taxa de letalidade, sobretudo na região de destino das pessoas que viviam nesses locais.

Por outro lado, em relação à intensificação da força policial na região fronteiriça, segunda política mencionada por Kleinschmitt (2016), constatou-se que houve diminuição na taxa de letalidade em Foz do Iguaçu. Essa redução, no entanto, aponta para uma verdadeira migração de práticas ilícitas para outros municípios da região: "O controle resultou na diminuição das taxas de letalidade em Foz do Iguaçu, em detrimento da difusão e do aumento das práticas ilícitas e das letalidades nos municípios vizinhos" (KLEINSCHMITT, 2016, p. 50).

Essa análise evidencia o descompasso entre ações estatais que objetivam controlar práticas ilícitas que têm espaço na região de fronteira e o que de fato tem constituído essa região. Não se trata de discutir o mérito de uma ou outra atividade considerada ilícita, no entanto é mais do que necessário que ações como as perpetradas pelo Estado e analisadas por Kleinschmitt (2016) sejam pensadas em compasso com o que existe na região, ou seja, nem todas as dinâmicas sociais presentes na região de fronteira podem ser meramente classificadas como atividades ilícitas. Há vida e há trabalho permeando essas relações.

Essas análises que buscam tornar visíveis o entrelaçamento entre a criminalidade e a letalidade com políticas de controle, e que acabam por embaralhar a ideia de lícito e ilícito, apontam para os meandros da extensão do conceito de licitude e se entrelaçam com a vida e o trabalho de muitas pessoas pertencentes a esse território fronteiriço.

\section{TRÂNSITOS FRONTEIRIÇOS E SUAS SINGULARIDADES}

As ambiguidades dessa região não traduzem apenas as relações de trabalho e seus efeitos, pois os trânsitos fronteiriços também constituem uma das características socioculturais desse espaço, materializadas por práticas ambíguas de controle que, ora os enrijecem, ora os tornam flexíveis, de forma que "os limites e o controle fronteiriço são acionados segundo conjunturas" (MOURA; CARDOSO, 2014, p. 266).

Equivocadamente, atribui-se apenas ao processo de globalização da economia a intensificação dos trânsitos fronteiriços ou até mesmo sua existência (SOUZA, 2003, p. 17). Nesse processo, segundo essa análise, há uma suposta intensificação da mobilidade que se tornaria ilimitada. Entre as razões principais - mas não exclusivas - encontra-se o aumento e a manutenção da desigualdade socioeconômica entre os povos, decorrentes de interesses públicos e privados que buscam êxitos comerciais, industriais, agrícolas e cambiais, em detrimento da criação ou do fortalecimento de condições capazes de oferecer uma vida menos desigual e com dignidade aos cidadãos dos países da fronteira trinacional.

Embora os efeitos desse processo possam ser mais perceptíveis em fluxos migratórios transnacionais aqui compreendidos como aqueles que necessariamente conduzem cidadãos de um país a outro - as mobilidades transfronteiriças, diretamente, respondem às grandes diferenças socioeconômicas entre os três países.

Essas desigualdades, além de intensificarem o trânsito de pessoas, também apontam para uma forma específica de movimentação, a de cidadãos que, apesar de não deixarem seu país para fixar residência em outro, vivem e se movimentam pelas fronteiras. Essa movimentação (trânsito transfronteiriço) muitas vezes, 
é equiparada a um processo migratório com todas as características de entrada e saída de um país que esse processo envolve.

Assim, por exemplo, quando cidadãos brasileiros que residem em Foz do Iguaçu cruzam a fronteira do Brasil para trabalhar ou fazer compras na cidade de Puerto Iguazú, na Argentina, sua passagem é condicionada ao registro de entrada e saída naquele país. Essa situação é bastante diferente da que ocorre com a cidade paraguaia de Ciudad Del Este, na qual não há controle migratório algum para os cidadãos brasileiros que se destinam àquela cidade. É também o que ocorre no lado brasileiro da fronteira, tanto para os cidadãos argentinos quanto para os paraguaios que entram no Brasil pelas cidades de Puerto Iguazú e de Ciudad Del Este, onde atualmente não há controle migratório algum.

Uma das tentativas para regulamentar os fluxos migratórios com vistas ao trabalho e à residência, no âmbito do Mercosul, resultou no Acordo sobre residência para nacionais dos Estados-Partes do Mercado Comum do Sul - Mercosul - Bolívia e Chile. A assinatura do Acordo ocorreu em dezembro de 2002, durante a XXIII Reunião do Conselho do Mercado Comum, em Brasília, cuja promulgação no Brasil, deu-se por meio do Decreto $\mathrm{n}^{\circ}$ 6.975, de 7 de outubro de 2009. Esse Acordo trata da possibilidade de o nacional de um Estado-Parte poder residir legalmente no território de outro Estado-Parte, mediante o cumprimento de alguns requisitos, que têm na nacionalidade um elemento importante, que deverá ser demonstrado para que a concessão de residência em um determinado Estado seja deferida. Dessa maneira,

se por um lado há, no campo dos direitos humanos e do direito internacional humanitário, forte proteção jurídica àqueles que migram, por outro lado, há nas normas de direito nacional uma espécie de vinculação entre a nacionalidade dos sujeitos de direitos e o acesso a direitos (GEDIEL, 2017, p. 469).

Reconhece-se por meio do Acordo que "a implementação de uma política de livre circulação de pessoas na região é essencial para a consecução desses objetivos" (BRASIL, 2009). O que se visualiza não é a instalação de uma política que favoreça a movimentação de pessoas entre os Estados que compõem o Mercosul, mas a adoção de uma política que atenda aos interesses do Bloco, o que pode apontar para mobilidades como instrumentos para o alcance de outros fins. Em matéria de mobilidade humana, no entanto, o objetivo é maior e se materializa no reconhecimento do direito à migração (OBERMAN, 2016), como uma característica que precisa ser fortalecida para que a própria integração latino-americana o seja.

Outro marco jurídico-normativo bastante importante para a compreensão das relações que se estabelecem na região da fronteira, mais especificamente na fronteira entre o Brasil e a Argentina, com as cidades de Foz do Iguaçu e Puerto Iguazú, é o Acordo sobre Localidades Fronteiriças Vinculadas, ${ }^{8}$ firmado pela República Argentina e pelo Brasil, em 30 de novembro de 2005, em Puerto Iguazú. Apesar de ter sido firmado em 2005, foi promulgado pelo Brasil apenas em 2016, por meio do Decreto $n^{\circ}$ 8.636, de 13 de janeiro de 2016.

Os dois Estados têm a expectativa de que o Acordo se constitua em uma ferramenta que possa "facilitar a convivência das localidades fronteiriças vinculadas e impulsar sua integração através de um tratamento diferenciado à população em matéria econômica, de trânsito, de regime trabalhista e de acesso aos serviços públicos e de educação" (BRASIL, 2016a).

É reconhecida a necessidade de que a convivência nas localidades que fazem fronteira entre o Brasil e a Argentina, especificamente nas cidades arroladas no Acordo, seja facilitada, por meio de um "tratamento diferenciado" das demais regiões do país. Esse tratamento diferenciado deveria contemplar diversas áreas, entre as quais a econômica, a de movimentação de pessoas nessas regiões, o regime trabalhista e o acesso a serviços públicos e aos de educação.

As motivações apresentadas nesses dois Acordos são importantes, por que reconhecem os fluxos migratórios como um instrumento pela busca e pelo acesso a direitos, e, também, por que tratam da região de fronteira como um espaço "desigual", no qual o exercício de direitos basilares, como o trabalho, a saúde e a educação, ocorre com características bastante diversas do que acontece no restante do país. Essas motivações

\footnotetext{
8 Para os efeitos desse acordo, são consideradas Localidades Fronteiriças Vinculadas: Foz do Iguaçu -Puerto Iguazú; Capanema - Andresito; Barracão/Dionísio Cerqueira - Bernardo de Irigoyen; Porto Mauá - Alba Posse; Porto Xavier - San Javier; São Borja - Santo Tomé; Itaqui Alvear; Uruguaiana - Paso de los Libres; Barra do Quaraí - Monte Caseros.
} 
apontam, ainda, para dissonâncias entre o que se propõe nas poucas iniciativas que tentam pensar a mobilidade fronteiriça e as dinâmicas sociais na região.

$\mathrm{O}$ artigo $1^{\circ}$ do Acordo sobre Localidades Fronteiriças Vinculadas, por exemplo, estabelece a possibilidade de acesso à Carteira de Trânsito Vicinal Fronteiriço a todos os cidadãos que possuam domicílio nas localidades estabelecidas pelo Acordo. Por meio desse documento permite-se que seus titulares detenham vários direitos e prerrogativas, entre os quais se destacam as atividades trabalhistas, a serem realizadas em condição de equiparação com os nacionais, inclusive quanto aos requisitos de formação e exercício da profissão.

O Acordo assegura a esses trabalhadores acesso ao ensino público e atendimento médico por meio do serviço público de saúde, ambos em condições de igualdade com os nacionais e pautados no princípio da reciprocidade, além do acesso aos serviços de comércio e a produtos de subsistência. O prazo de validade da permanência estipulado, inicialmente, em cinco anos, está condicionado à abrangência territorial com suas prerrogativas, registrado na Carteira de Trânsito Vicinal Fronteiriço. Nesse limite territorial o titular está autorizado a exercer seus direitos, exatamente como também dispôs a Lei no 13.445 (Lei de Migração), de 24 de maio de 2017, no artigo $23, \S 2^{\circ}$, de forma que "o direito interno de cada país se organiza em torno da soberania exercida sobre o território nacional [...]. A atuação do direito nacional, interno, em relação aos estrangeiros é, em princípio, regulatória e restritiva de direitos já assegurados aos nacionais" (GEDIEL, 2017, p. 468).

A hipótese apresentada na norma anterior é bastante distante daquela apresentada nas pesquisas analisadas neste artigo e também se distancia sobremaneira do intensivo controle fronteiriço de entrada e saída entre as cidades de Puerto Iguazú e Foz do Iguaçu, apontando para relações marcadas por ambivalências e ambiguidades que estão além do controle da criminalidade e de práticas ilícitas - como aquelas tipificadas nas ações no âmbito do circuito sacoleiro - mas também estão presentes no controle de quem entra e de quem sai de cada uma das cidades. Aliás, ambivalências que em momentos de pandemia como o atual, causado pelo avanço da Covid-19, tornam-se mais evidentes.

Durante o fechamento da fronteira por força da pandemia, cidadãos argentinos ${ }^{9}$ tiveram sua entrada proibida no país, permanecendo por vários dias na Ponte da Fraternidade entre as cidades de Puerto Iguazú e Foz do Iguaçu e cidadãos paraguaios ${ }^{10}$ foram retidos na Ponte da Amizade entre Foz do Iguaçu e Ciudad Del Este. Em ambos os casos, os acessos foram negados aos nacionais dos respectivos Estados, sob o argumento de questões relacionadas à saúde e à prevenção do vírus. Não apenas o "estrangeiro" passa a ser considerado inimigo, mas também o nacional que pretende retornar.

Basta lembrar que, até recentemente, em matéria de legislação brasileira, os migrantes também eram tratados como "estrangeiros", como inimigos do Estado (SEYFERTH, 1997), sob a égide do Estatuto do Estrangeiro (BRASIL, 1980), revogado pela Lei de Migração - Lei no 13.445, de 24 de maio de 2017. A racionalidade que permeava a Lei revogada mostrava-se hostil em relação à presença de "estrangeiros" em território nacional, dificultava fluxos migratórios e definia migrantes como verdadeiras ameaças ao país, facilitando a entrada de cidadãos de algumas nacionalidades e dificultando a entrada de outros (SEYFERTH, 1997).

Do ponto de vista normativo, o tratamento dispensado àqueles que não são considerados nacionais ${ }^{11}$ sofreu profundas alterações quando analisado com os princípios norteadores do instrumento ${ }^{12}$ regulador anterior, que tratava da situação jurídica do "estrangeiro" no Brasil. As marcas culturais e institucionais deixadas pelas normas recentemente revogadas continuam vigentes nas práticas dos agentes públicos aduaneiros, das polícias de todos os países vizinhos e são facilmente aprofundadas diante de eventos que colocam em risco o Estado-Nação, suas finalidades constitucionalmente declaradas e interesses nem sempre expressos.

\footnotetext{
9 PARAGUASSU, Lisandra. Argentinos deixam o Brasil, não podem entrar na Argentina e ficam presos na Ponte da Fraternidade. Disponível em: https://www.terra.com.br. Acesso em: 15 abr. 2020.

${ }^{10}$ Disponível em: https://g1.globo.com. Acesso em: 14 abr. 2020.

${ }^{11}$ Além de estabelecer parâmetros ao acesso de cidadãos migrantes no território nacional, a nova Lei também apresenta avanços em relação ao brasileiro que se desloca a outros países, ao estabelecer princípios e diretrizes para uma política pública voltada aos migrantes (BRASIL, 2017b, artigo 77).

12 BRASIL. Lei $n^{\circ} 6.815$, de 19 de agosto de 1980.
} 
Discussões como essa passam necessariamente pela consideração de fluxos migratórios e mobilidades fronteiriças como direito. Nesse sentido, ao questionar se existiria um direito humano a migrar, ${ }^{13}$ David Miller $(2016$, p. 11) destaca que, na verdade, atualmente a prerrogativa de determinar quem deve ser admitido ou não em um Estado tem se tornado um direito amplamente reivindicado pelos Estados.

Além disso, para Miller, esse direito é reforçado pela existência de um conjunto de instrumentos que reafirmam e atualizam permanentemente a ideia de um direito dos Estados em determinar quem são os autorizados a ingressar em seus limites territoriais. Esses instrumentos materializam-se nos controles de fronteira e nas medidas que são adotadas sempre que alguém não preenche as "condições necessárias" para ingresso em um determinado Estado. Segundo Miller, se houvesse um direito à migração todo esse conjunto de instrumentos e prerrogativas, utilizado pelos Estados para determinar quem ingressa ou não em seus limites, seria inaceitável.

Em outra direção, Kieran Oberman (2016, p. 32) considera que "people have a human right to immigrate to other states". ${ }^{14}$ Partindo da premissa de que restrições migratórias agem como limitadores das liberdades individuais, ele destaca que as pessoas têm interesses essenciais (não necessariamente pessoais) que precisam ser defendidos. Para ele, esses interesses estão protegidos por outros direitos humanos que têm aplicabilidade no âmbito interno dos Estados.

Oberman discute a moralidade da qual se revestem os direitos humanos que confere às pessoas o direito a migrar, sobretudo porque os direitos humanos legais são aqueles que a lei prevê e destaca que "no current legal human rights document includes a human right to immigrate"15 (2016, p. 34). Se não há na lei o reconhecimento da migração como direito, é a moralidade dos direitos humanos que atribui força normativa à sua efetividade. Nesse sentido, os direitos humanos

visam à integração dos migrantes de vários países envolvidos em processos de mobilidade humana, entre territórios regidos por distintas ordens jurídicas nacionais. Sua finalidade é basicamente protetiva e ampliativa de direitos dos estrangeiros em migração. Os direitos humanos e o direito internacional humanitário têm, portanto, finalidades distintas dos direitos nacionais, pois partem de diferentes postulados e contêm elementos decorrentes da acomodação da tradição jurídica romana às necessidades do comércio e da convivência entre povos (GEDIEL, 2017, p. 469).

Nesse viés, além das discussões que compreendem ou não a migração como direito, há inúmeras situações nas quais o elemento volitivo de migrar não está presente. São essas situações que são permanentemente vivenciadas nessa fronteira. São relações marcadas pelas dinâmicas do próprio espaço e que constituem a vida das pessoas que moram na região. A naturalização dessas dinâmicas tem se constituído em verdadeiro desafio aos Estados-nacionais, porque as fronteiras não se resumem a linhas demarcatórias, ao contrário, são verdadeiros espaços dotados de significados socioeconômicos, políticos, culturais, entre tantos outros que qualificam esse espaço como local diverso e intercultural ${ }^{16}$ capaz de separar, mas, também, de aproximar Estados e estabelecer relações e conflitos decorrentes dessa aproximação.

\section{CONSIDERAÇÕES FINAIS}

As diversas compreensões que podem ser retiradas das análises sobre a fronteira, sobretudo aquela relacionada aos limites do Estado-Nação, revelam a pluralidade de estratégias e ações estatais capazes de limitar ou ampliar, correlativamente, as mobilidades fronteiriças. Assim, conceber a fronteira de uma ou de

\footnotetext{
${ }_{13}$ Para David Miller (2016, p. 11), "a human right to immigrate means, a universal right to cross the borders of any state and remain within them for as long as one chooses". "Um direito humano a imigrar significa um direito universal de cruzar fronteiras de qualquer Estado e nele permanecer pelo tempo que se desejar" (tradução nossa).

14 "As pessoas têm direito humano a imigrar a outros Estados" (tradução nossa).

15 "Os atuais institutos legais sobre direitos humanos não incluem um direito humano a imigrar" (tradução nossa).

${ }^{16}$ Apesar de haver sensíveis diferenças entre os conceitos de multiculturalidade e interculturalidade, não é objeto deste trabalho a análise semântico-terminológica de ambos os termos. Objetiva-se, tão somente, acenar para a compreensão desse espaço como uma realidade na qual inúmeras diversidades dialogam.
} 
outra maneira interfere, diretamente, na formulação e execução dessas ações estatais, ao mesmo tempo que contribui para a construção de dinâmicas sociais constituídas histórica e culturalmente.

Nos espaços existentes entre essas concepções e entre as ações que delas emergem estão verdadeiras bifocalidades, atos e realidades que se constituem em dissonâncias entre as tentativas de compreensão da fronteira como limite de um Estado e a fronteira como campo de possibilidades e tudo o que essas possibilidades significam e carregam em si. Essas dissonâncias, como foi demonstrado, aponta para relações ambíguas que fazem conceitos como legal e ilegal, lícito e ilícito serem aproximados e se tornarem semanticamente polissêmicos.

Por mais que não se trate de transformar o lícito em ilícito ou o ilícito em lícito, a aproximação entre os dois institutos, bem como o espaço e as lacunas erigidas entre ambos revelam que compreender a fronteira apenas como limite territorial é muito mais uma relação arbitrária do que uma relação de adequação ou consideração da região como um território fronteiriço, que se constitui em espaço social com outros significados para a população que ali habita.

Essa relação arbitrária, muitas vezes marcada por controles migratórios, desempenha um papel fundamental na manutenção de desigualdades globais e na limitação da liberdade humana (CARENS, 2013), de maneira que "if a just world had states, they would be states with open borders" ${ }^{17 "}$ (p. 287).

São essas inconformidades perpetradas pelas maneiras de compreender a fronteira que se objetivou descrever ao longo deste artigo, sobretudo para demonstrar como uma mesma ação ou atividade pode ser compreendida de mais de uma maneira e que essas compreensões agem diretamente na configuração e na reconfiguração da fronteira trinacional entre Argentina, Brasil e Paraguai.

\section{REFERÊNCIAS}

ALBUQUERQUE, José Lindomar Coelho. A dinâmica das fronteiras: deslocamento e circulação dos "brasiguaios" entre os limites nacionais. Horizontes Antropológicos, Porto Alegre, v. 15, n. 31, p. 137-166, jun. 2009. Disponível em: http://www.scielo.br/ scielo.php?script=sci_arttext\&pid=S0104-71832009000100006. Acesso em: 10 mar. 2020.

ALBUQUERQUE, José Lindomar Coelho. As dinâmicas das fronteiras: os brasiguaios entre o Brasil e o Paraguai. São Paulo: Annablume, 2010.

ANDERSON, Benedict R. Comunidades imaginadas: reflexões sobre a origem e a difusão do nacionalismo. São Paulo: Companhia das Letras, 2008.

ARANHA, Renato Muchiuti. De conjuntos habitacionais a bairros: a construção e o desmonte das vilas de Itaipu (1974-2012). 2013. 113 f. Dissertação (Mestrado em História) - Universidade do Estado de Santa Catarina, 2013.

BARBOSA, Fernando Cesar Mendes. Relações entre trabalho, cidadania e dinâmicas sociais em região de fronteira: ponderações sobre uma solução sociojurídica. In: Revista de Estudos Jurídicos da Unesp, Franca, SP, v. 20, n. 31, p. 61-81, 2016.

BARBOSA, Fernando Cesar Mendes. Trabalhador nas fronteiras: relações de trabalho e cidadania nas dinâmicas sociais da fronteira trinacional. 2018. 156 p. Dissertação (Mestrado em Ciência Jurídica) - Universidade Estadual do Norte do Paraná - Uenp, Jacarezinho/PR, 2018.

BRASIL. Decreto n. 350, de 21 de novembro de 1991. Promulga o Tratado para a Constituição de um Mercado Comum entre a República Argentina, a República Federativa do Brasil, a República do Paraguai e a República Oriental do Uruguai (Tratado Mercosul). Poder Legislativo, Brasília, DF, 21 nov. 1991. Disponível em: http://www.planalto.gov.br/ccivil_03/decreto/1990-1994/ d0350.htm. Acesso em: 5 abr. 2020.

BRASIL. Decreto n. 9.199, de 20 de novembro de 2017. Regulamenta a Lei n. 13.445, de 24 de maio de 2017, que institui a Lei de Migração. Diário Oficial da União, Poder Legislativo, Brasília, DF, 21 nov. 2017a. Disponível em: http://www.planalto.gov.br/ ccivil_03/_ato2015-2018/2017/decreto/D9199.htm. Acesso em: 20 mar. 2020

BRASIL. Decreto $n^{\circ}$ 8.636, de 13 de janeiro de 2016. Promulga o Acordo entre a República Federativa do Brasil e a República Argentina sobre Localidades Fronteiriças Vinculadas, firmado em Puerto Iguazú, em 30 de novembro de 2005 . Diário Oficial da União, Poder Legislativo, Brasília, DF, 14 jan. 2016a. Disponível em: http://www.planalto.gov.br/ccivil_03/_ato20152018/2016/decreto/D8636.htm. Acesso em: 5 mar. 2020.

\footnotetext{
17 "Se um mundo justo tivesse Estados, eles seriam Estados com fronteiras abertas" (CARENS, 2013, p. 287.) (Tradução nossa)
} 
BRASIL. Decreto no 6.975, de 7 de outubro de 2009. Promulga o Acordo sobre Residência para Nacionais dos Estados Partes do Mercado Comum do Sul - Mercosul, Bolívia e Chile, assinado por ocasião da XXIII Reunião do Conselho do Mercado Comum, realizada em Brasília nos dias 5 e 6 de dezembro de 2002. Diário Oficial da União, Poder Legislativo, Brasília, DF, 8 dez. 2009. Disponível em: http://www.planalto.gov.br/ccivil_03/_ato2007-2010/2009/decreto/d6975.htm. Acesso em: 10 mar. 2020.

BRASIL. Decreto no 7.496, de 8 de junho de 2011. Institui o Plano Estratégico de Fronteiras. Disponível em: http://www.planalto.gov.br. Acesso em: 12 abr. 2020.

BRASIL. Decreto no 8.903, de 16 de novembro de 2016b. Institui o Programa de Proteção Integrada de Fronteiras e organiza a atuação de unidades da administração pública federal para sua execução. Disponível em: http://www.planalto.gov.br. Acesso em: 12 abr. 2020.

BRASIL. Lei n. 13.445, de 24 de maio de 2017. Institui a lei de migração. Diário Oficial da União, Poder Legislativo, Brasília, DF, 25 maio. 2017b. Disponível em: http://www.planalto.gov.br. Acesso em: 16 set. 2019.

Brasil. Lei no 6.815, de 19 de agosto de 1980. Define a situação jurídica do estrangeiro no Brasil. Disponível em: http://www. planalto.gov.br/ccivil_03/leis/I6815.htm. Acesso em: 12 abr. 2020.

CARDIN, Eric Gustavo. A expansão do capital e as dinâmicas das fronteiras. Jundiaí: Paco Editorial, 2015.

CARDIN, Eric Gustavo. Ação racional e cotidiano: notas para o estudo dos trabalhadores da Tríplice Fronteira. In: SILVA, Regina Coeli Machado e; SANTOS, Maria Elena Pires (org.). Cenários em perspectiva: diversidades na tríplice fronteira. Cascavel: Edunioeste, 2011. p. 121-139.

CARDIN, Eric Gustavo; ALBUQUERQUE, José Lindomar Coelho. Fronteiras e deslocamentos. Revista Brasileira de Sociologia, v. 6, n. 12, p. 114-131, 2018.

CARDOSO, N.; MOURA, R. Mobilidade transfronteiriça: entre o diverso e o efêmero. Caderno Ipardes: Estudos e Pesquisas, v. 1, n. 2, p. 205-222, dez. 2012.

CARENS, J. The Ethics of Immigration. Oxford: Oxford University Press, 2013. p. 173-287.

CARNEIRO, Cynthia Soares. Migrações internacionais e precarização do trabalho: o contexto global, os acordos de residência do Mercosul e os imigrantes sul-americanos no Brasil. Argumenta Journal Law, Jacarezinho, PR, Brasil, n. 26, p. 337-374, 2017. CATTA, Luiz Eduardo Pena. A face da desordem: pobreza e estratégias de sobrevivência em uma cidade de fronteira (Foz do Iguaçu/1964-1992). São Paulo: Blucher Acadêmico, 2009.

CATTA, Luiz Eduardo Pena. O cotidiano de uma fronteira: a perversidade da modernidade. Cascavel: Edunioeste, 2002.

CATTA, Luiz Eduardo Pena. Pobreza e marginalidade na tríplice fronteira. In: SILVA, Regina Coeli Machado e; SANTOS, Maria Elena Pires (org.). Cenários em perspectiva: diversidades na tríplice fronteira. Cascavel: Edunioeste, 2011. p. 91-120.

DA SILVA, I.; PIRES SANTOS, M. E.; JUNG, N. M. Multilinguismo e política linguística: análise de uma paisagem linguística transfronteiriça. Domínios de Lingu@gem, v. 10, n. 4, p. 1.257-1.277, 28 nov. 2016.

FARINA, Bernardo Cunha. Trabalhadores fronteiriços na tríplice fronteira: confronto entre a igualdade jurídica e a realidade. 2015. 210 p. Dissertação (Mestrado em Sociedade, Cultura e Fronteiras) - Universidade Estadual do Oeste do Paraná, Unioeste, Foz do Iguaçu, 2015.

GEDIEL, José Antônio Peres. Migração irregular. In: CAVALCANTI, Leonardo et al. (org.). Dicionário crítico de migrações internacionais. Brasília: Editora Universidade de Brasília, 2017.

KLEINSCHMITT, Sandra Cristina. As mortes violentas e as políticas de controle na Tríplice Fronteira. Tempo da Ciência, Toledo, v. 23, n. 46, p. 40-59, 2016.

LIMA, Fernando Raphael Ferro de. O desenvolvimento regional na fronteira Foz do Iguaçu/BR - Ciudad del Este/PY. $2011.165 \mathrm{f}$. Tese (Doutorado em Geografia) - Universidade Federal do Paraná, Setor de Ciências da Terra, Curitiba, 2011.

MILLER, David. Is there a human right to immigrate? In: FINE, Sarah; YPI, Lea (org.). Migration in Political Theory: The Ethics of Movement and Membership. Oxford: Oxford University Press, 2016.

MOURA, R.; CARDOSO, N. A. Mobilidade transfronteiriça: o ir e vir na fronteira do possível. In: SILVA, E. F.; GEDIEL, J. A. P.; TRAUCZYNSKI, S. C. (org.). Direitos humanos e políticas públicas. 1. ed. Curitiba: Universidade Positivo, 2014. p. 263-280. V. 1.

NASCIMENTO, Wagner Cipriano do. As relações de poder no contexto político-econômico de Foz do Iguaçu/PR. 2010.232 f. Dissertação (Mestrado em Geografia) - Universidade Estadual de Maringá, Centro de Ciências Humanas, Letras e Artes, Maringá, 2010.

NEVES, Alex Jorge et al. (org.). Segurança pública nas fronteiras, diagnóstico socioeconômico e demográfico: estratégia nacional de segurança pública nas fronteiras (Enafron). Brasília: Ministério da Justiça e Cidadania; Secretaria Nacional de Segurança Pública, 2016.

OBERMAN, Kieran. Immigration as a human right. In: FINE, Sarah; YPI, Lea (org.). Migration in Political Theory: The Ethics of Movement and Membership. Oxford: Oxford University Press, 2016. 


\section{Direito自 \\ Debate}

FRONTEIRA: TRÂNSITOS, SENSOS E DISSENSOS COMPARTILHADOS

José Antônio Peres Gediel - Fernando Cesar Mendes Barbosa

PARAGUASSU, Lisandra. Argentinos deixam o Brasil, não podem entrar na Argentina e ficam presos na ponte da Fraternidade. Disponível em: https://www.terra.com.br. Acesso em: 15 abr. 2020.

RABOSSI, Fernando. Bridging Three Nations. In: NACLA Report on the Americas, 51:1, p. 65-71, 2019. DOI: 10.1080/10714839.2019.1593693

RABOSSI, Fernando. Conflito sobre ruedas: trabajando sobre el Puente de La Amistad. In: SILVA, Regina Coeli Machado e; SANTOS, Maria Elena Pires (org.). Cenários em perspectiva: diversidades na tríplice fronteira. Cascavel: Edunioeste, 2011. p. 141-165.

SEYFERTH, Giralda. A assimilação dos imigrantes como questão nacional. Mana, Rio de Janeiro, v. 3, n. 1, p. 95-131, abr. 1997. Disponível em: http://www.scielo.br. Acesso em: 12 abr. 2020.

SILVA, Regina Coeli Machado e. Entre fronteiras: imigração e identidade de grupos árabes em Foz do Iguaçu. In: SILVA, Regina Coeli Machado e; SANTOS, Maria Elena Pires (org.). Cenários em perspectiva: diversidades na tríplice fronteira. Cascavel: Edunioeste, 2011. p. 69-90.

SILVA, Regina Coeli Machado e. Fronteiras nacionais e configurações socioculturais. In: SILVA, Regina Coeli Machado e; SANTOS, Maria Elena Pires (org.). Interdisciplinaridade e Fronteiras: movimentos, identidades e configurações. Cascavel: Edunioeste, 2012. p. 13-29.

SILVA, Regina Coeli Machado e; CAMPOS, Maria José. Políticas do segredo: incursões etnográficas no campo da (i)legalidade fiscal. Ambivalências, v. 6, n. 12. p. 19-46, 2018.

SLOMP, Angélica Cândido Nogara. A tutela juslaboral do migrante transfronteiriço sob a perspectiva dos direitos humanos. 2014. 214 f. Dissertação (Mestrado em Direito) - Faculdade de Direito da Universidade de São Paulo, São Paulo, 2014.

SOTUYOU, Patrícia Claudia Godoy. Segregação urbana: estudo de caso das vilas de Itaipu. 1998. 150 p. Dissertação (Mestrado) - Universidade Federal de Santa Catarina, Florianópolis, 1998.

SOUZA, Jessé. A construção social da subcidadania: para uma sociologia política da modernidade periférica. Belo Horizonte: Editora UFMG; Rio de Janeiro: luperj, 2003. 207 p. (Coleção origens).

WACHOWICZ, Ruy C. Obrageros, mensus e colonos: história do oeste paranaense. Curitiba: Vicentina, 1987. 